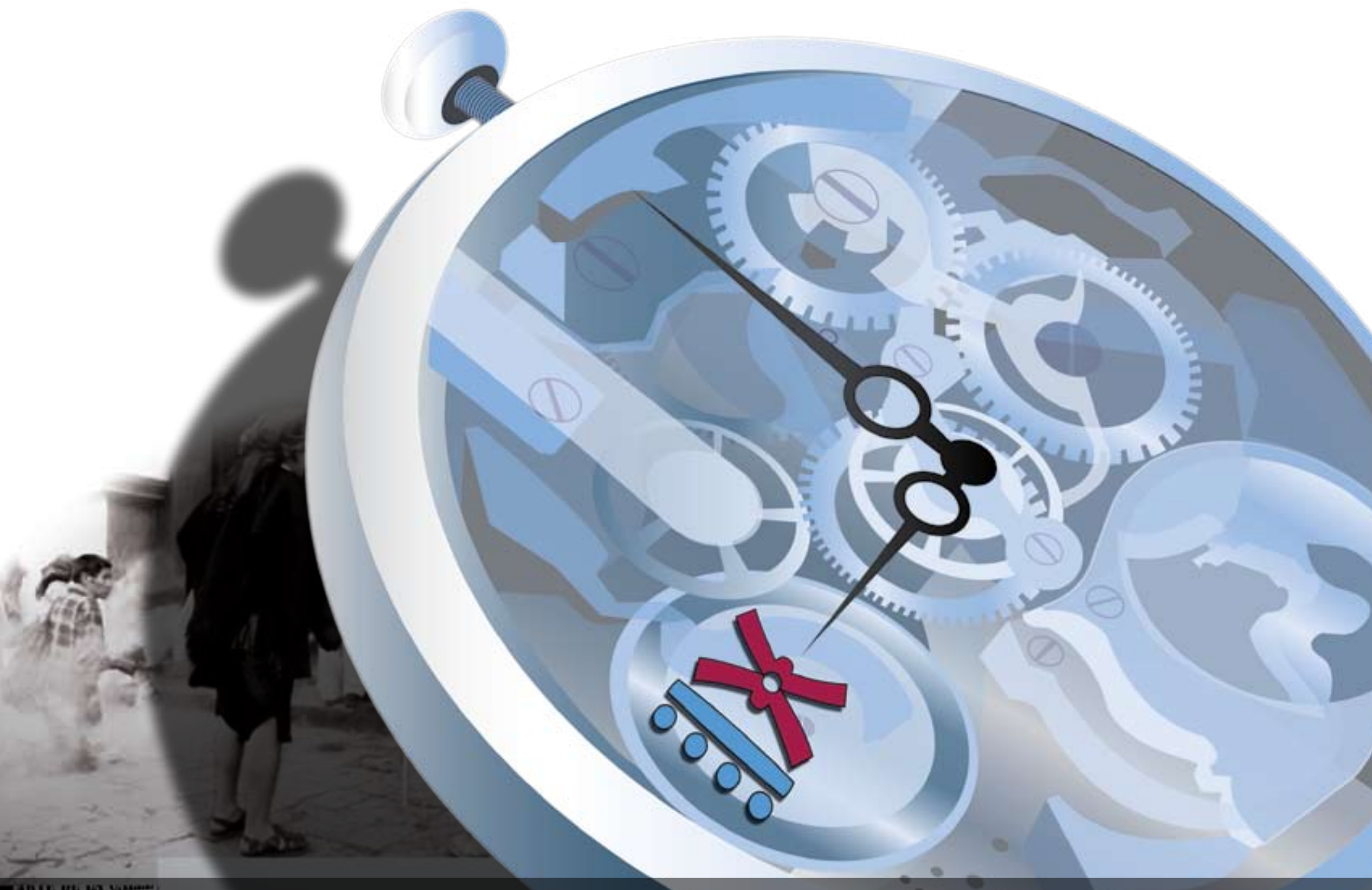
8 .

CENTROAMERICANO

Universidad de Costa Rica

ISSN 1409-469X

Fecha de recepción: 15 de mayo 2008 Fecha de aceptación: 30 de mayo 2008

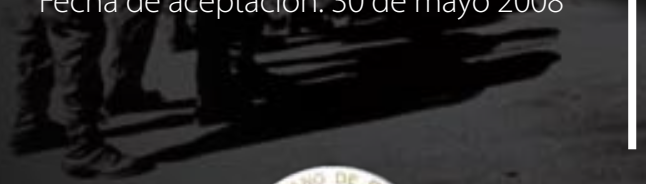

Historia Regional del Pacífico El preámbulo de una historia social comparada, 1821- 1950

Miembros del Consejo Editorial:

Dr. Ronny Viales, Dr. Juan José Marín

Editores Técnicos:

Allan Fonseca, Andrés Cruz, Gabriela Soto.
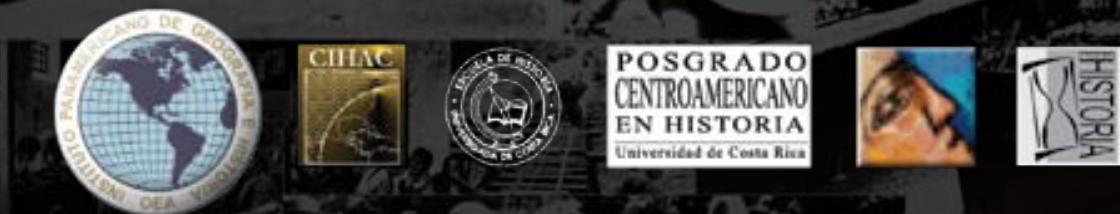
Indexaciones: Repositorio de Revistas UCR, DIALNET, Latindex, REDALYC Directorio y recolector de recursos digitales del Ministerio de Cultura de España, Directory of Open Access Journals. Diálogos Revista Electrónica de Historia ISSN 1409- 469X. Número especial 2008. Dirección web: http://historia.fcs.ucr.ac.cr/dialogos.htm

\title{
Historia Regional del Pacífico El preámbulo de una historia social comparada, 1821- $1950\left({ }^{1}\right)$
}

\author{
Dr. Juan José Marín Hernández
}

Coordinador Programa de Historia Regional

CIHAC

Correo electrónico jmarin@cariari.ucr.ac.cr

$1 \quad$ Este trabajo es un borrador que se preparó para el IX Congreso de Historia. Actualmente, la investigación avanza en archivos, por ello es conveniente advertir al lector que el trabajo posee un carácter exploratorio. 
La historia regional del Pacífico se revela rápidamente como una problemática interesante para cualquier historiador, principalmente porque desde el principio el investigador se comienza a cuestionar todos los procesos históricos recopilados y dados por ciertos por la historia oficial. La perspectiva iconoclasta si bien de por si puede resultar fascinante por destruir los fetiches; por denunciar las desviaciones y los errores de interpretación; y por fomentar el interés por restituir la inquietud por estudiar los procesos no es suficiente. En efecto a pesar de su evidente contribución, no puede ni debe serlo. Así por ejemplo, la historia regional comparada va mucho más allá del deconstruir por deconstruir, dentro de ella esto no es fructífero, pues exige al historiador además de la crítica (sea simple o compleja) la tarea (y diríamos el compromiso) de pensar en instrumentos de trabajo teórico metodológicos nuevos y acordes a la realidad socio cultural a la que se debe. $\left({ }^{2}\right)$

Parte de los quehaceres que se le imponen al historiador social de la región es repensar las categorías básicas de trabajo como espacio y tiempo hasta reflexionar sobre las estrategias metodológicas que den cuerpo y contenido a las categorías intermedias de análisis. La tarea de repensar lo básico es magistralmente desarrollada por Bernardo García, quien indica que las regiones deben verse como:

... un producto histórico enlazado con un espacio físico. Son un terreno en que se expresan con gran intimidad las relaciones entre la geografía y la historia o, para decirlo de otra manera, entre espacio y tiempo.... Porque una región es al espacio lo que una época al tiempo, es decir, una parte del total $\left({ }^{3}\right)$.

La visión de García es importante, pues al concebir a la región como una construcción social histórica lleva a los investigadores de lo regional el plantear que la región es en sí misma una hipótesis a investigar. Lo anterior es significativo, pues en esta ponencia se parte de que la región del Pacífico es una hipótesis de trabajo. Como tal el Pacífico no es una realidad per se, 2 Véase Martínez Anel y Melchor Jaime Las categorías y el análisis regional. En: Monografias.com. Dirección web: http://www.monografias.com/trabajos11/catereg/catereg.shtml y Miño Grijalva Manuel . Existe la Historia Regional?. El Colegio de México. Dirección web http://historiamexicana.colmex.mx/pdf/13/ art_13 1968_18038.pdf y Abel Albet ¿Regiones singulares y regiones sin lugares? Reconsiderando el estudio de lo regional y lo local en el contexto de la geografía postmoderna. En: Boletín de la A.G.E. No. 32 - 2001, págs. 35-52

3 García Bernardo. Las regiones de México. Brevario Geográfico e histórico. Colegio de México. México 2008, pp. 11 
enmarcada por una serie de accidentes geográficos o por una simple correlación de una serie de elementos de tipo físico y socioeconómico. Las relaciones sociales, económicas y políticas junto con los sentimientos, la identidad el sentido de pertenencia o las representaciones sociales, solo para mencionar algunas, crean un tejido de vivencias que hacen que un espacio se experimente en forma diferenciada. Por esos motivos una región puede ser percibida bajo diferentes criterios, o conceptuarse dentro de un supuesto espacio homogéneo diversas regiones; puede diferenciarse de otras por su tamaño, riqueza económico, número de habitantes, tipo de estructura productiva o desarrollo funcional, y aún así seguir siendo considerada como una región. $\left(^{4}\right)$

Hasta hace poco tiempo, en el pensamiento popular y de los medios de comunicación, el pacífico solía a reducirse a la ciudad de Puntarenas, y como tal, asociada a la historia del país (léase valle central). Se consideraba como un simple apéndice de los designios de la clase cafetalera y de los empresarios josefinos. No obstante, como se verá en la ponencia esto fue mucho más complejo.

En suma, este trabajo, aunque preliminar tiene como objetivos

1- Analizar la región pacífica como una construcción socio histórica edificada en complejos procesos socio culturales y económicas.

2- Determinar comparativamente los procesos de vinculación entre la región pacífica con la meseta central.

Las fuentes son diversas y han sido recolectadas en la plataforma de investigación del programa Historia Regional Comparada del CIHAC ( ${ }^{5}$ ), entre ellas destacan los anuarios estadísticos, los censos agrícolas y bases nominales y la base de datos de mapas y los discursos presidenciales. Así como diversas referencias periodísticas.

Dado el carácter exploratorio y de diagnóstico que posee este trabajo, se decidió vivirlo en tres secciones. La primera se denomina "El Pacifico. Una y diversa o una región con historia", en ella se pretende visualizar la historicidad de este espacio el cual es cruzado por procesos que

4 García Bernardo. Las regiones de México. Brevario Geográfico e histórico. Colegio de México.

México 2008, pp. 11-38

5 Véase http://moodle-historia.fcs.ucr.ac.cr/ 
van desde el doblamiento hasta el discurso regionalista, pasando por el sentido de pertenencia, la creación de territorios y la consolidación de una red de territorios articulados bajo el concepto de región. El segundo aparado denominado "Horizonte temporal. Procesos con vivencia disímil" pretende comparar los procesos nacionales con los ocurridos en el pacífico y a partir de ahí lanzar algunas hipótesis provisionales de trabajo. Finalmente, en el tercer apartado se realizan algunas observaciones para comprender las diferencias en los procesos ocurridos entre el centro y esta periferia.

\section{EL PACIFICO. UNA Y DIVERSA O UNA REGIÓN CON HISTORIA}

Los territorios y las regiones son espacios donde se plasman las huellas de la cultura y la identidad, así como las acciones y relaciones de estos en un tiempo y espacio determinado. Un atributo de esta simbiosis ha sido la permanente inquietud de crear espacios acotados ya sea para reafirmar la identidad o favorecer el control social. Horacio Capel, junto con otros geógrafos y cientistas en ciencias sociales, han destacado el papel del control social en esa relación hermanada y más específicamente el papel del poder. Para Capel este permite incorporar su acción sobre hombres espacialmente localizados, así como la dominación del espacio. ( $\left.{ }^{6}\right)$

Particularmente, esa visión resulta sumamente importante, pues permite pensar tanto los perfiles físico - geográficos como las distintas relaciones humanas desarrolladas dentro de ellos y la capacidad de crear, privilegiar, segmentar, marginalizar o invisibilizar diversos espacios para ejercer el poder y su subsiguiente resistencia. Solo tendiendo esta consideración se pueden entender las diversas divisiones y cambios en las regionalizaciones.

En efecto, la costa del pacífico ha sido históricamente cambiante y transformada. Por tal razón se puede considerar como antítesis de la historiografía regional que ha figurado a Costa Rica como un país sin indígenas, poblado desde el centro por los tico meseteños; el carácter blanco y europeo; así como la idea de que el grano de oro, y eventualmente, el banano fueron monopólicos en el desarrollo económico social. Si bien dichos estereotipos fueron creados y recreados por los liberales y luego reedificados por la llamada historiografía socialdemócrata, todavía en 1923 6 Capel Horacio (editor). Los espacios acotados, Geografía y dominación social. PPU. Barcelona. 1990, p.1 
los mapas escolares recordaban, aunque fuera parcialmente, las territorialidades indígenas entre 1502 y 1821 . (Véase mapa 1)

Mapa 1. Distribución espacial de las regiones en los denominados periodos de descubrimiento. conauista v colonia de Costa Rica 1502 v 1821.

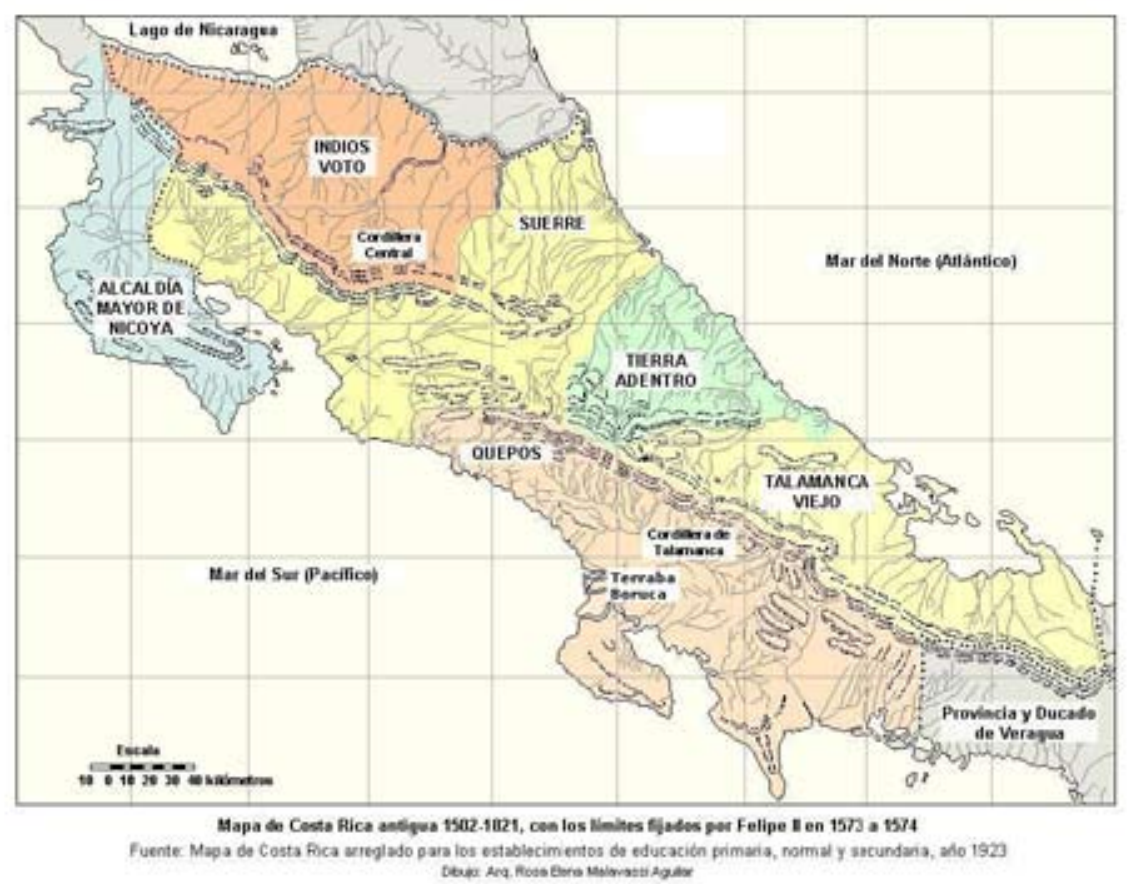

El mapa de 1923 destacaba los diferentes territorios indígenas, si bien con gran cantidad de impresiones como están demostrando los trabajos de la antropóloga Margarita Bolaños en el Caribe con los actuales habitantes de indígenas. La regionalización observada en el mapa 1 fue poco retenida por la memoria oficial del estado. El cual tuvo un espíritu modernista el cual pretendía invisibilizar a los grupos indígenas. De hecho, la costa pacífica históricamente ha tenido una presencia significativa de indígenas, tan visible como en el Atlántico, pero sistemáticamente olvidada.

Lo anterior es historiográficamente significativo, pues todavía no se ha podido visualizar los cambios y procesos de regionalización entre 1502 y 1675 ó entre ese año y 1821. Asimismo, se desconoce el peso de las diferentes regiones indígenas en la estructuración de nuevas 
regionalizaciones, lo cual no sólo es ignorado sino también poco trabajado. Si bien, los arqueólogos profesionales han avanzado sobre los desarrollos territoriales de los diferentes cacicazgos y han podido caracterizar las particularidades de los grupos indígenas precolombinos y coloniales con respecto a las denominadas áreas culturales, el dialogo entre arqueología e historiografía no ha avanzado mucho.

Como bien, ha señalado Juan Carlos Solórzano, durante la primera mitad del siglo diecinueve no se sabía prácticamente nada del pasado colonial ni prehispánico de Costa Rica, siendo los liberales quienes comenzaron a recrear un pasado sin indígenas o exótico en el mejor de los casos. ( ${ }^{7}$ ) En este último caso, Costa Rica no fue diferente a otros países centroamericanos. Así el mapa 1 no parece distanciarse mucho de la experiencia hondureña donde la historiografía y las políticas trataron de "mayanizar" aún a aquellas poblaciones indígenas que no habían pertenecido a dicha cultura en el período prehispánico. La gran ignorancia del pasado colonial figuró una territorialización interesada. Tanto Quesada como Solórzano han avalado la idea de que la historiografía liberal pretendía justificar las fronteras del estado nación. $\left({ }^{8}\right)$

Durante el siglo XIX, los liberales en su proyecto nacional impulsaron un proyecto construcción nacional que aunque fue progresivo poco a poco trató de homogenizar la historia y el papel de la denominada "Meseta Central". Por ello no es de extrañar que el mapa no. 2 solo visualice el centro y norte del país, de este modo el mapa de 1861 ilustra los territorios donde se construiría el "ecumen" nacional, es decir el un núcleo en el centro del país al que se adherían los puertos del San Juan del Norte (conocido por los ingleses como Greytown) y Puntarenas. Ambos puertos enlazados con el naciente modelo agroexportador sustentado por el éxito del café.

Mapa no. 2 Zona Norte de Costa Rica, 1861

7 Solórzano Juan Carlos. Reflexiones en torno a la historiografía y la arqueología en Costa Rica durante el siglo XIX. En Anuario de Estudios Centroamericanos, Universidad de Costa Rica, vol 27 no 1. 2001. Dirección web http://cariari.ucr.ac.cr/ anuario/solorzano5.pdf

$8 \quad$ Quesada Juan Rafael. Historia de la historiografía costarricense, 1821-1940. San José, Editorial Universidad de Costa Rica. 2001 


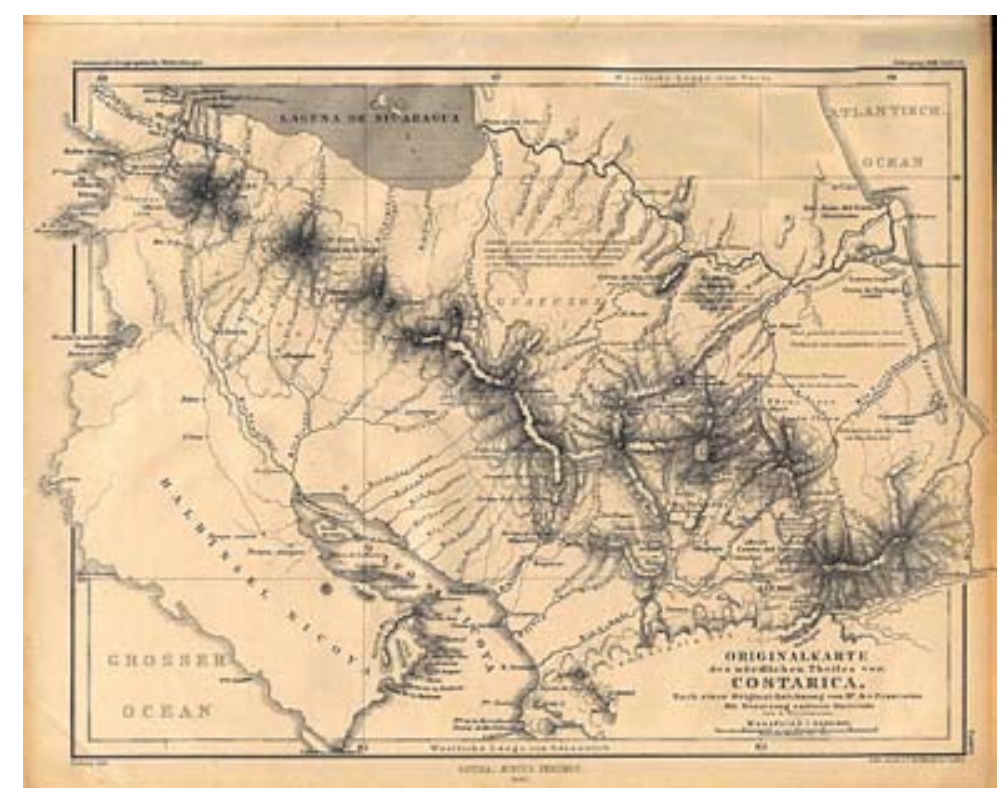

Fuente Mittheilungen aus Justus Perthes' Geographischer Anstalt uber Wichtige Neue Erforschungen auf dem Gesammtgebiete der Geographie von del Dr. A. Petermann. Volumen 7. 1861

También debe indicarse que el mapa no. 2 evidencia como los gobiernos liberales y conservadores intentaron hacer de su "ecumen" un bastión que pudiera primero sustentar el modelo agroexportador y consolidar el poder del estado. Si bien, se desconoce todavía los grados de resistencia, colaboración o unión de la élites locales, parece que para la naciente oligarquía cafetalera y sus aliados el eje centro - norte era fundamental. La consolidación no quedaba exenta de peligros, las arremetidas tanto británicas como estadounidenses; las crispaciones del resto del istmo y la expansión (o deseos de expansión de otras elites locales).

Si bien, debe analizarse con detalle los discursos de los jefes de estado y presidentes para comprender mejor la funcionalización del espacio en los diferentes periodos, pero especialmente el desarrollado entre 1848 y 1880, el mapa no 2 sugiere elementos interesantes. Es posible que el interés despertado por el mismo fuera porque el mismo evidenciaba la viabilidad de la apropiación territorial. Y bajo esa lógica se quería potenciar la capacidad de asumir una nueva regionalización del territorio. En términos de la hegemonía de la clase dominante, el eje territorial permitiría: 
a- poder de influenciar y controlar los procesos productivos, de comercialización y exportación

b- distribuir las funciones productivas entre diversos territorios y tendencialmente controlar los excedentes,

c- capacidad de conocer la movilización de productos y personas

d- dar forma a la extensión y consolidación de autoridades y funcionarios que lleven no solo la lógica estatal, sino también de la reproducción social

Con todo lo anterior queremos indicar que debe verse el espacio, en este caso el Pacífico, como un espacio manipulado y moldeado por determinados intereses sociales, económicos y culturales, con la intención de adecuarse a los proyectos políticos determinados. El mapa no. 3 evidencia como en tan solo seis décadas el proyecto territorial había cambiado. Entre 1864 y 1930 hubo 9 re estructuraciones administrativas $(1864 ; 1883 ; 1892 ; 1900 ; 1910,1915,1920,1927$ y 1930), a las que se agregaron las de 1940 y 1950. Todas ellas dieron forma a un proceso de integración muy diferente a la visualizada en $1861\left({ }^{9}\right)$

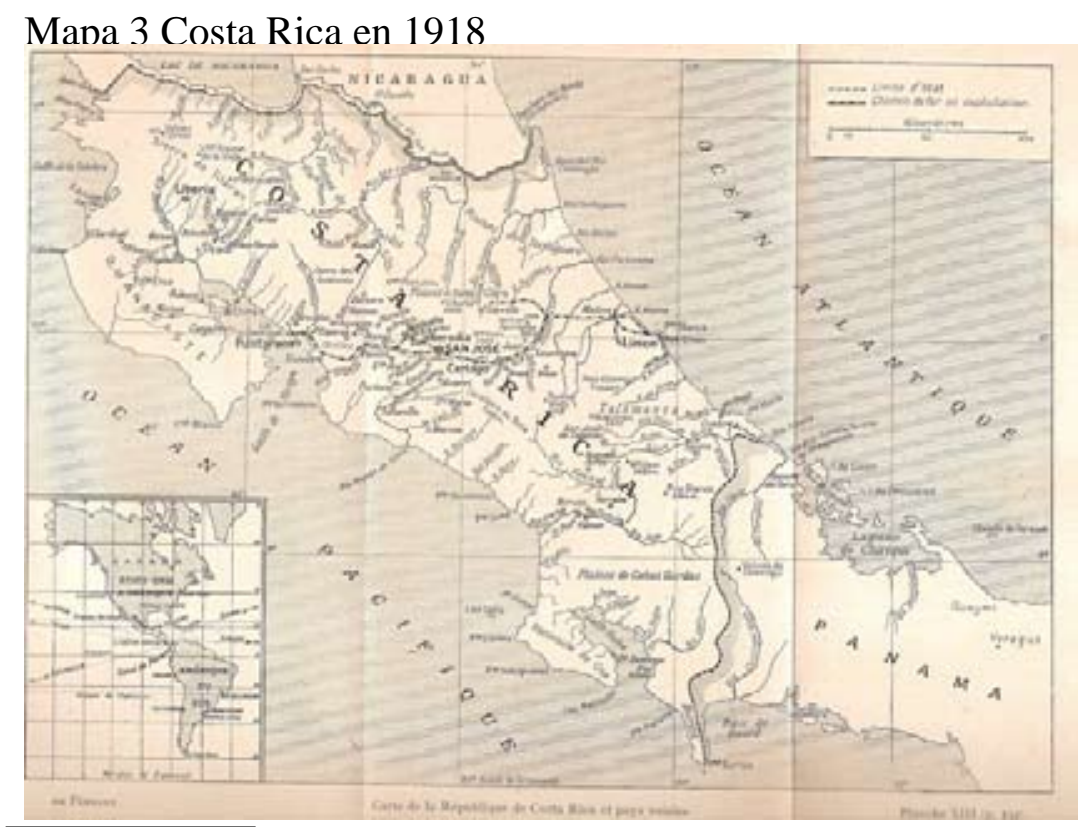

$9 \quad$ Sobre la evolución de los cantones y sus poblaciones véase Alvarado Ronulfo. La división territorial administrativa de Costa Rica: Evolución Histórica y situación actual. San José, IFAM. 2003 
El mapa no 3 sólo es una evidencia de cómo el espacio es un escenario donde ocurren procesos y se materializan vivencias, sentimientos y con ellos los actores sociales que configuran y reconfiguran una las territorializaciones y las dimensiones regionales.

Por su parte, el mapa no 4 evidencia un fenómeno que debemos reconstruir el cual esta en proceso de elaboración para todas las regiones del país, el cual es la estructura productiva y sus implicaciones con otras esferas. Por ello, el estudio de las regiones lejos de ser un análisis determinista da paso a las contradicciones sociales que se reflejan en diversos niveles. Al productivo y de equipamiento urbano, se unen por un lado, la defensa del hogar, de la comunidad y del sentido de lugar, asociados a las formas en que cada grupo desarrolla sus medios de subsistencia y visones del mundo. Por otro, la creación de mecanismos de identidad asociados a la procedencia geográfica, el desarrollo laboral, el sentido de clase y las lealtades (religiosas, políticas y culturales.

Ambos niveles no implican de ninguna forma armonía, pues están no solo en construcción sino que además en ellas se evidencian diferentes tendencias que van desde las formas de producción hasta las desigualdades socio culturales. 


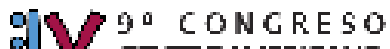

Indexaciones: Repositorio de Revistas UCR, DIALNET, Latindex, REDALYC Directorio y recolector de recursos digitales del Ministerio de Cultura de España, Directory of Open Access Journals.

Diálogos Revista Electrónica de Historia ISSN 1409- 469X. Número especial 2008. Dirección web: http://historia.fcs.ucr.ac.cr/dialogos.htm

Mada 4 Regiones agrícolas 1950

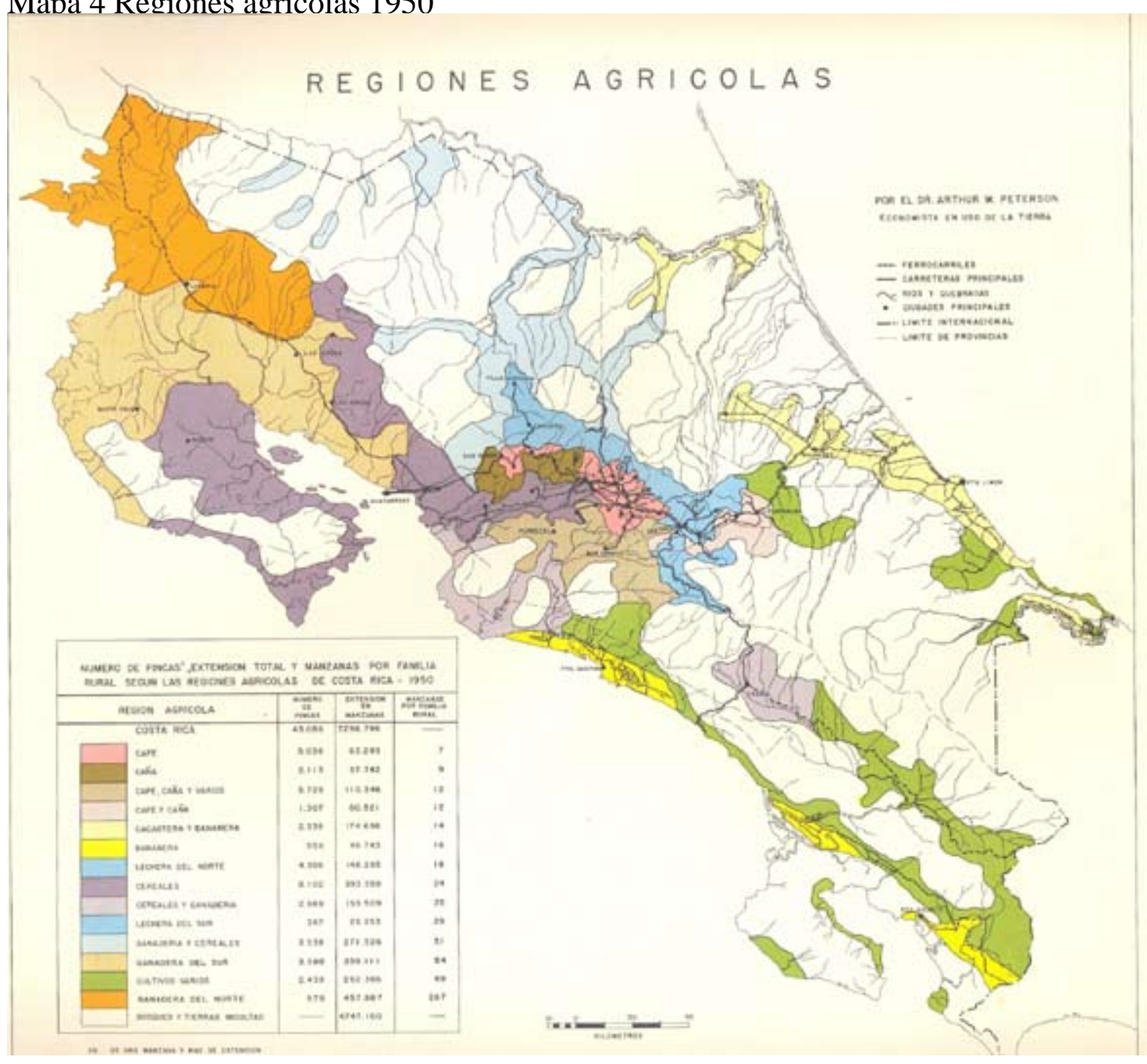

Finalmente, debemos preguntarnos que espacio surgirá en el Pacífico cuando se esta rearticulando la producción nacional y donde las tendencias de crecimiento apuntan a una mayor vinculación con las economías de Asia.

Mapa 5. El Pacífico como punto de expansión. La redefinición de un espacio. 


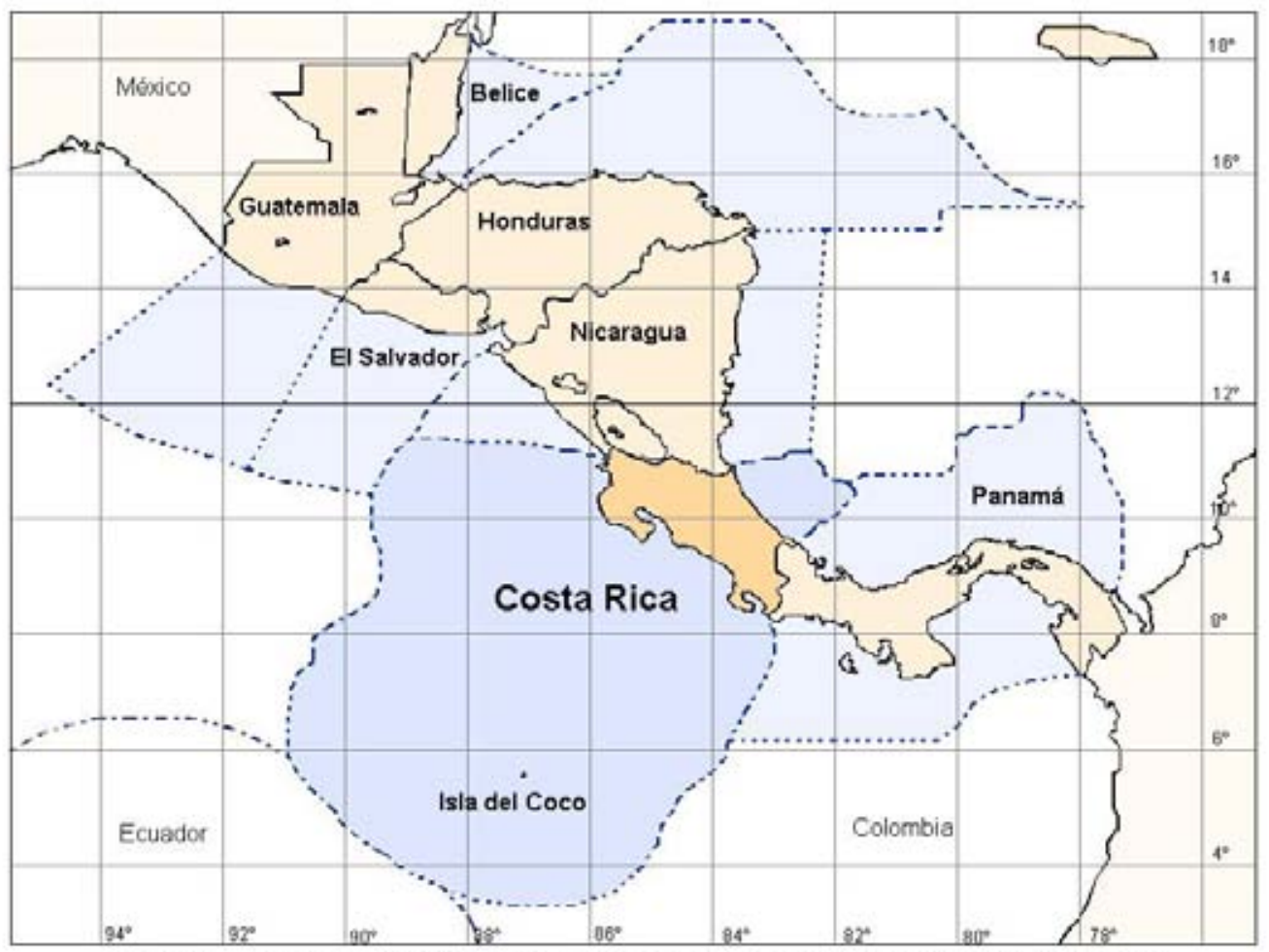

Territorios de los paises centroamericanos con su mar patrimonial y territorial aproximados

Fuente: La gran Costa Rica, Guillermo Quirós, Oceanógrafo Fisico

Como se puede observar en el mapa no 5 también existe dentro de diferentes grupos sociales una mayor conciencia de la "oceanidad" del país. La cual puede tendencialmente cambiar la estructura de la región pacífica.

En todo caso, este breve e incompleto repaso desea señalar que:

a- Además de los contextos físico geográficos existen en las regiones condiciones históricas, culturales, e incluso étnicas. Pero que uno de los elementos esenciales es observar en estos espacios (cambiantes, trasmutables y yuxtapuestos) como el ligamen de los diferentes grupos y comunidades está el poder.

b- Que el poder es un elemento fundamental e imprescindible para entender a la región como un producto social, el cual no solo es un reflejo de las estructuras sociales sino también de las vivencias de los diferentes grupos sociales, los cuales generan esperanzas, expectativas 
y visiones de mundo y de su región diferentes a los grupos y clases hegemónicas

c- Que el poder actúa a través de la organización espacial pero que no por ello lo hace en forma absoluta ni armónica. En esa organización espacial y social hay conflictos y actores sociales con sus propios proyectos sociales de renovación socio espacial

d- Que el espacio no es solo un escenario del drama humano, sino que pude convertirse en un factor activo de la producción y justificación de comportamientos sociales, al crear identidades y atributos de clase que justifican su proyecto social.

e- Que la organización del espacio a través de las regiones no es inocente, sino que también contribuye en el propósito de moldear o doblegar las voluntades, como se trató de realizar en los procesos de segmentación e invisibilización de los grupos indígenas, o la reconstrucción imaginaria de las particularidades regionales, para insertarlas o excluirlas del proyecto nacional. De este modo debe tenerse en cuenta que las regiones pueden ser diseñadas o rediseñadas con miras de facilitar la vigilancia, el proyecto económico dominante o para intentar doblegar las voluntades o dirigirlas hacia un comportamiento determinado.

f- Que en las regiones se encuentra la idea de alianzas de poder con elites locales que pueden unirse a procesos de coerción y mecanismos ideológicos particulares dando origen a especificidades regionales de control y desarrollo socio económico y cultural

g- Que en ese proceso de alianzas entre poder central y local; entre elites regionales y nacionales se desarrolla una serie de símbolos de poder que procuran articulan una imagen de unidad nacional, a pesar de las diferencias.

En suma, la reorganización espacial y su incidencia en la vida social son fundamentales en los estudios regionales. Hasta hace poco tiempo, los historiadores se han sentido abrumados por los constantes cambios en el desarrollo regional; los alteraciones abismales en el tamaño de los cantones y sus frecuentes divisiones; la dificultad de encontrar una "llave" espacial básica del cantón que permita seguir el desenvolvimiento económico o la simple contrariedad de ubicar a los actores y procesos en un espacio más o menos cercanos a la realidad. Apuros y complicaciones que requieren diferentes opciones tales como la triangulación metodológica, el cruce de datos como pueden ser las bases de mapas coropléticos con las vías de comunicación; movimientos sociales o procesos de población, además de estrategias como la dendrología 
Las interrogantes básicas para el pacífico como región y que pretender guiar la sistematización de este trabajo; cuáles fueron las transformaciones socio espaciales, territoriales y regionales más significativas en el pacífico; cuales de ellos crearon discursos regionalistas, sentimientos de pertinencia y apropiación del lugar; cómo se articularon las diferentes territorialidades en regiones; qué papel jugó el poder y las estructuraciones productivas en la configuración de la región; cómo se distribuyeron los recursos tanto entre las regiones como entre los grupos sociales que la habitan; y qué consecuencias tuvo la disposición espacial de la red burocrática, entre otras interrogantes que nos deja visualizar a la región como una construcción social

\section{HORIZONTE TEMPORAL. PROCESOS CON VIVENCIA DISÍMIL}

La historia tradicional de Costa Rica ha elaborado una historia muy simple y plana del pacífico. Se bosqueja la presencia de cuatro grupos indígenas importantes: Chorotegas, Huetares, Térrabas y Borucas (eventualmente se cita a los Corobicies) obviando diferencias culturales; evoluciones históricas y estandarizando los cacicazgos a su máxima expresión. Salvo notables excepciones se presenta el descubrimiento y conquista de los pueblos indígenas como armonioso y pacífico y el brutal descenso demográfico es explicado por la escasez de indígenas. Gil González y Pedrarias de Dávila quienes entre 1513 y 1519 recorrieron toda la costa pacífica del actual Costa Rica. $\left({ }^{10}\right)$

Vagamente, se considera un poblamiento primario entre 1720 y 1765 fomentado por un nativo panameño (Miguel Antonio de Unanué) que visibiliza el comercio y contactos marítimos de la costa Pacífica con Nicaragua, Guatemala, El Salvador, Panamá, México y Suramérica

10 Tanto esta reconstrucción como las ilustraciones de los marcos temporales los datos son tomados de Oficial. Atlas cantonal de Costa Rica. San José. IFAM

1984; González Cleto. El puerto de Puntarenas: algo de su historia. Imprenta Gutenbertg. San José. 1933M; Aguilar Hilda. Apuntos cronológicos del Puerto de Puntarenas: 25 aniversario de la ciudad de Puntarenas. IFAM - Municipalidad de Puntarenas. 1983; Nuñez Francisco María. De Puntarenas a Golfo Dulce, diario de viaje excursión organizada por la Municipalidad de Puntarenas. San José. Tipografía Nacional. 1914; Quijano Alberto. Costa Rica de Ayer y Hoy: 1800-1939. Imprenta Borrasé. 1939 y Valverde Arabela. La ciudad de Puntarenas: Una aproximación a su historia económica y social, 1858 - 1930. Tesis de Licenciatura en Historia. Universidad de Costa Rica. 1997.

Debe indicarse que a partir de dichas obras se realizó una base de datos socio temporal a cargo del suscrito. La misma esta disponible en la plataforma de investigación del CIHAC programa de Historia Regional. 
(Perú y Colombia). Pero este tipo de contactos ha sido apenas considerado de este modo la escala interregional y su peso en la configuración del Pacífico es apenas avizorado. Todavía la importancia de estas colonias y vínculos es ignorado. Así por ejemplo e desconoce el peso de estos grupos en las protestas y anhelos de independencia española, o su papel en obligar a la elite meseteña la instauración de Puntarenas como puerto nacional y la imposición de que el ferrocarril llegará al Puerto y no a Caldera y Esparza como se pensaba desde la capital.

Más vago es el conocimiento sobre el papel de los pobladores en el conflicto de 1856, particularmente, con la creación de un panteón de héroes nacional diferente al instaurado por la oligarquía. Todavía la designación de Juan Rafael Mora Porras y José María Cañas resulta incomoda para la clase dominante, y su exclusión en el marco del Tratado de Libre Comercio por parte del gobierno de Arias Sánchez y de los diputados y empresarios aliados con dicha administración evidencian este elemento. En todo caso, el análisis tanto de las alianzas entre elites, la creación de imaginarios sociales y la creación de comunidades políticas imaginadas de tipo local y sus héroes aún debe estudiarse dada la otredad existente.

A partir de la consolidación del Estado Nación y de la estructura agroexportadora el puerto de Puntarenas ha aparecido aisladamente en el discurso historiográfico como apéndice del centro y luego, con la consolidación del Puerto de Limón como puerto principal, hizo que el puerto de Puntarenas pasara a ser considerado un espacio de segundo orden, aún cuando en la realidad poseía un gran dinamismo que seguía las tendencias del Pacífico Centroamericano. En su lugar se interiorizaba a puerto Caldera como el nuevo modelo de integración internacional.

Ahora bien, ese panorama lineal e insípido en la realidad es mucho más complejo con interconexiones, rupturas, vías y continuidades diferenciadas. Así por ejemplo, en la ilustración no 1 se observa como los marcos temporales del pacífico tuvieron sus propias particulares que comenzaron a caracterizar su espacio interregional desde muy temprano. Así por ejemplo la conquista se estos territorios se dio asociado los articulaciones entre Perú, México, Panamá y Centroamérica, las cuales a su vez cimentaron procesos autóctonos de conexión entre territorios que darían una unidad estructural, a través del cabotaje. Es impresionante, observar el peso de salvadoreños, chiricanos y mexicanos en el desarrollo del pacífico central, principalmente 
Indexaciones: Repositorio de Revistas UCR, DIALNET, Latindex, REDALYC Directorio y recolector de recursos digitales del Ministerio de Cultura de España, Directory of Open Access Journals. Diálogos Revista Electrónica de Historia ISSN 1409- 469X. Número especial 2008. Dirección web: http://historia.fcs.ucr.ac.cr/dialogos.htm

asociados a la explotación de perlas y fabricación de embarcaciones.

Asimismo, y en el proceso de conexiones inter regionales se desarrollaban nexos con el Centro del país. El cual por cierto fue conquistado desde el pacífico en un proceso espinoso y competitivo entre conquistadores, amén de la resistencia indígena

Ilustración no.1

Marco temporal comparativo entre el Pacífico y el Valle Central durante la Conquista y la Colonia

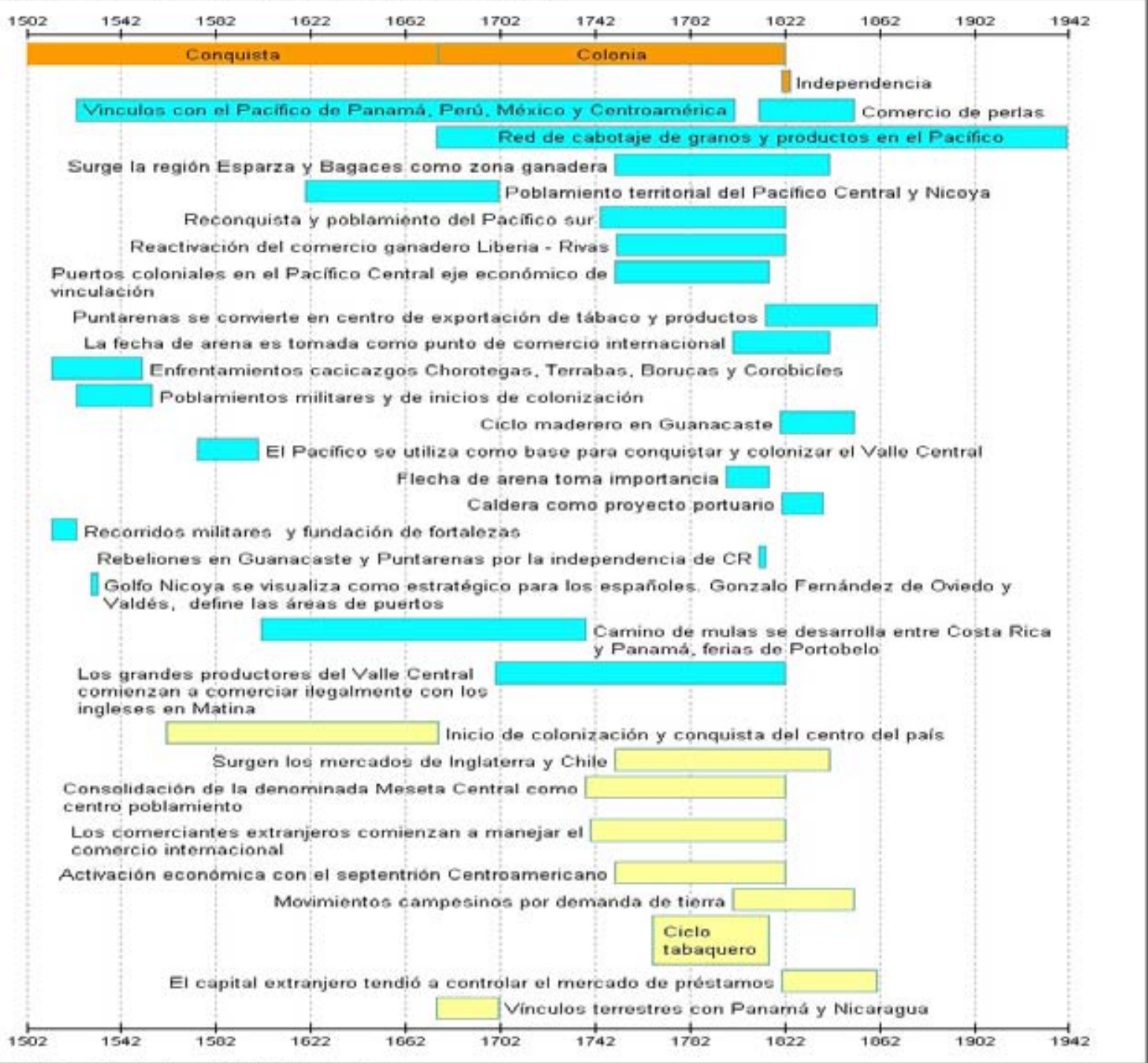


Como se puede observar de la ilustración no. 1 los articulaciones entre Pacífico y el Centro (después considerado "Meseta Central") fueron complementarias. Así por ejemplo, mientras por el mar se daba una rápida conexión con Chile, México y Perú, en el Valle Central las conexiones predominantes fueron terrestres con Nicaragua y Panamá. Eliminadas las ferias de Portobelo la elite del centro del país tuvo que negociar el proceso de vinculación con Chile e Inglaterra, de ahí que la élite porteña tuviera un punto privilegiado en aumentar las conexiones de los vallecentralisnos con el comercio internacional, a pesar de que estos tenían una experiencia amplia con el comercio ilegal por Matina y la desembocadura del San Juan. Tales procesos de comparación y contrastación aún son desconocidos y exigen un mayor análisis, en especial a lo desconectado que se ha presentado el tema de capitales extranjeros a fines del periodo colonial, sólo por citar uno

Asimismo, como se puede observar en la ilustración No.2 los ritmos en los procesos complejos y diferenciados pero vinculados entre el Pacífico y el Valle Central continuaron entre 1821 y 1948, con procesos que precedieron y siguieron después de ese marco temporal.

Así por ejemplo, la influencia del puerto inglés en la isla de San Lucas, la preponderancia de las casas comerciales en la lengüeta y la insistencia de crear el puerto en Puntarenas contra los designios de la elite "vallecentralina" todavía no son conocidos. Menos aún son entendidos los procesos que llevaron a crear una gran región central latitudinal que posteriormente uniría los dos puertos con la denominada "meseta". Y cómo ambos fenómenos, ayudaron a consolidar un modelo agroexportador notablemente exitoso, como bien lo ha señalado el economista e historiador Jorge León $\left({ }^{11}\right)$

Por su parte, en la ilustración no 3 evidencia la complejidad que significaron procesos como el fin de la frontera agrícola, la expansión diferenciada de la educación superior y desde luego la gran crisis de 1980

11 Exposición oral Jornadas del CIHAC : Evolución del comercio exterior y del transporte marítimo de Costa Rica, 1821-1900”. Seminario impartido por el Master Jorge León (2005e), el trabajo no se ha publicado. 
Ilustración 3

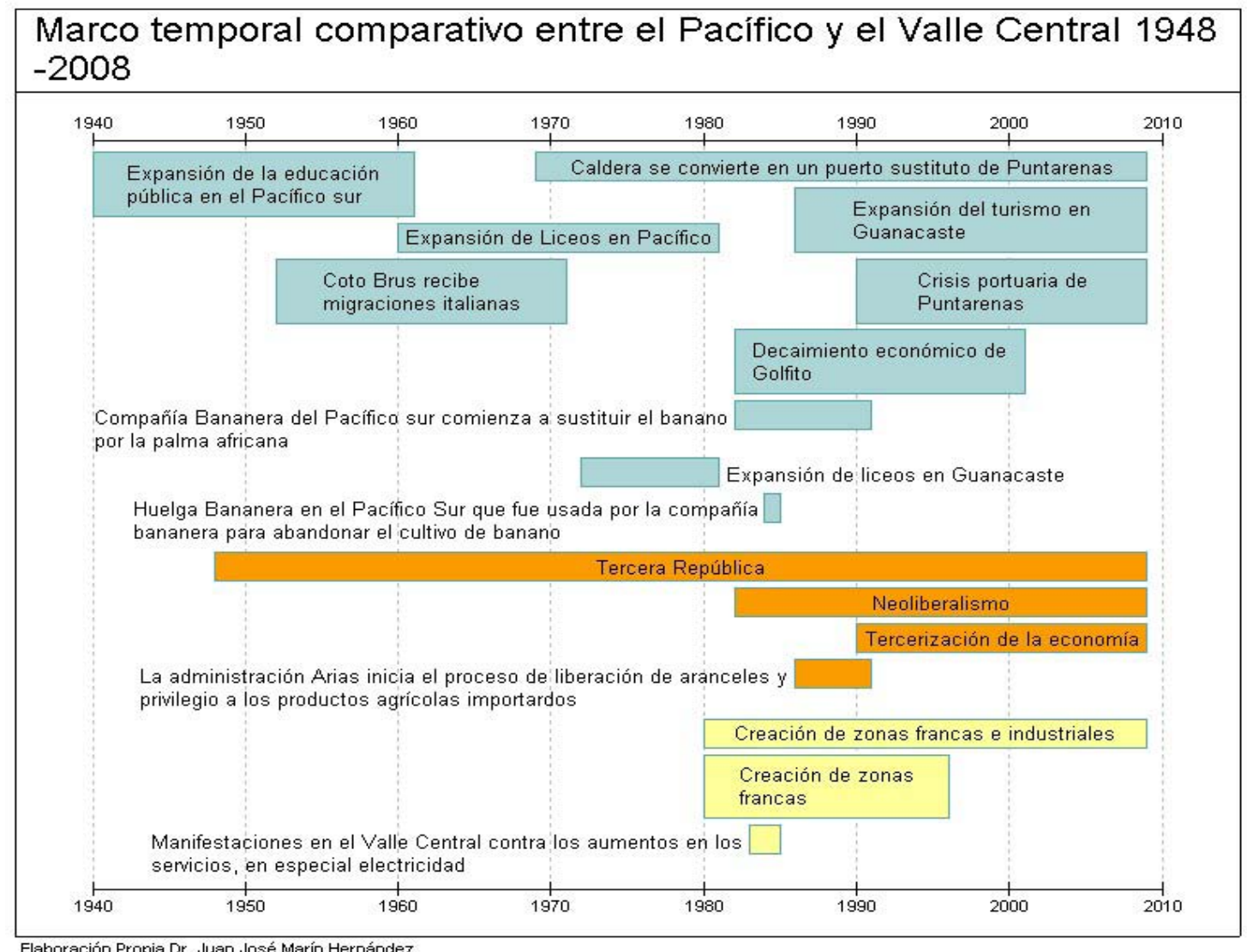

En suma, el panorama que evidencian los horizontes temporales, más que una interpretación acabada invitan a acercarse a la complejidad de los procesos regionales, antes que aceptar la linealidad de los procesos históricos. Por ello, la historia regional invita a analizar los efectos culturales, sociales y económicos y sus intrincadas conexiones con otros territorios y procesos. Sin duda, el reto del análisis histórico regional es la crear las herramientas de trabajo que den cuenta de la complejidad, pero que al mismo tiempo modifique las formas de ver, hacer y de escribir la historia nacional.

Hoy más que nunca a las preguntas ¿qué pasó? ¿Qué hubiese pasado si”? o ¿quién lo hizo? Pasaron a ser complementarias, pues no solo se pluralizaron sino que se problematizaron en 
¿qué cosas ocurrieron? ¿Con qué ritmo? ¿Cuáles fueron las diferencias? ¿Qué panoramas y qué relaciones se dieron entre procesos, actores sociales y territorios? Evidentemente esas preguntas no se resuelven añadiendo o quitando factores, sino más bien de un rico ejercicio de interpretar la plétora de eventos, hechos, y acontecimientos complejos y múltiples con sus interrelaciones, causas y derivaciones. Este tipo de planteamiento cuestiona la historia como algo inexorable, dado y lineal.

\section{PROCESOS DEL PACIFICO}

La complejidad señalada a nivel macro también invita a analizar los diferentes procesos dados en el pacífico. Es decir, comprender como dentro de una misma región se desarrollan subregiones, territorios y redes. El caso del pacífico es particularmente, valioso. La historia comparada de la misma permite visualizar los diferentes ritmos en los que se consolidaban los procesos. . $\left({ }^{12}\right)$

De esa forma la confluencia de hechos dentro de una región se configuran y se integran de manera diferenciada. Al interior del Pacífico las disparidades inter regionales muestran niveles de evolución distintivos. A manera de ejemplo, podemos destacar dos casos relacionados con el poblamiento y el equipamiento urbano.

Como se puede observar en el gráfico no.1 sobre el índice de crecimiento de la población el pacífico costarricense a pesar ser un punto inicial de colonización ha tenido en su conjunto un desarrollo lento. No obstante, esto contrasta con ciertos ejes como fue el de la lengüeta y sus alrededores.

Gráfico no.1

12 Véase Brinckmann Brinckmann. Desarrollo y desigualdad regional: El Ejemplo Delvalle de Río Pardo (Río Grande Do Sul, Brasil). En: Papeles de Geografía, No. 34. 2001, 69-84 


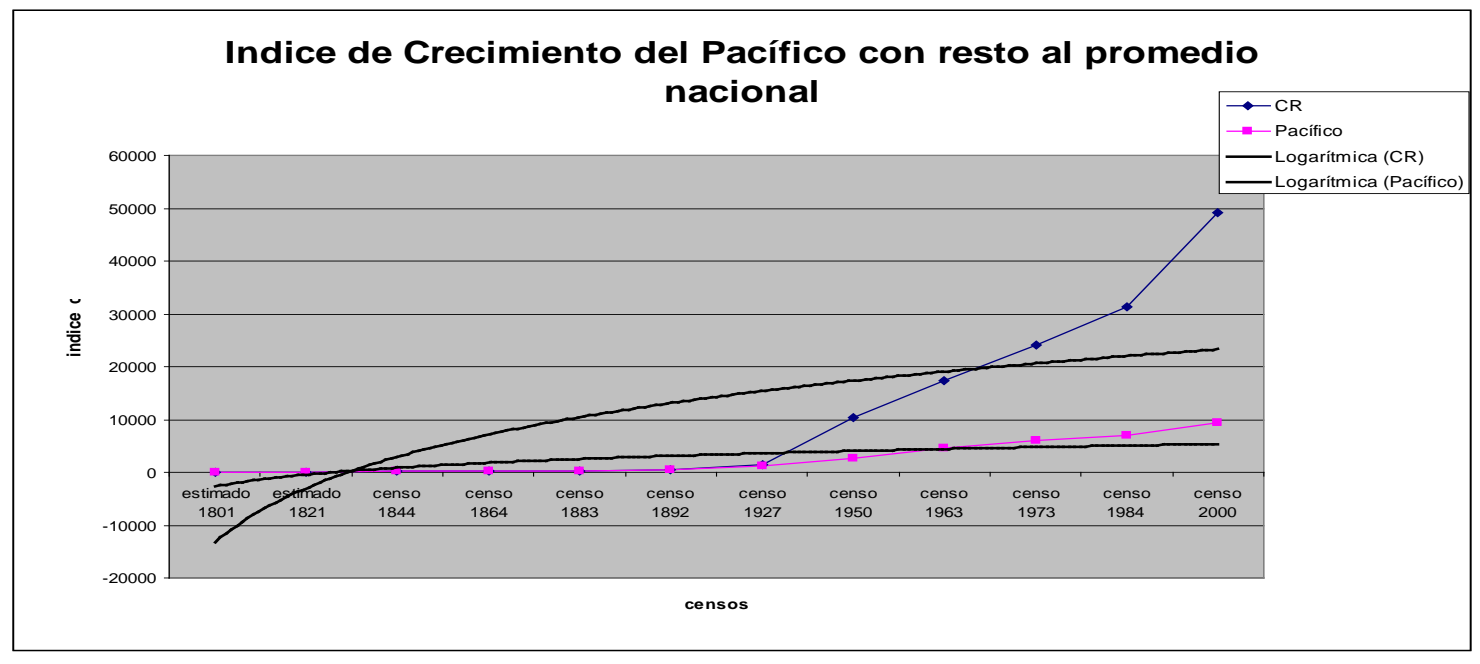

Si bien la gráfica por si mismo no permite comprender los procesos cualitativos del impacto brinda una idea del crecimiento diferenciado entre la costa pacífica y el resto del país. De momento, el cuadro 1 sobre el establecimiento de los cantones (la creación de los mismos obedece a criterios poblaciones y de incidencia política) evidencia como la costa pacífica tuvo un papel trascendental en los primeros años de la vida independiente y de la creación de la república, decreciendo paulatinamente.

cuadro no.1 Número de cantones creados por región 1848 - 1930

\begin{tabular}{|c|c|c|c|c|}
\hline LUGAR /AÑO & $\begin{array}{l}184 \\
1868\end{array}$ & $\begin{array}{l}186 \\
1889\end{array}$ & $\begin{array}{l}189 \\
1910\end{array}$ & $\begin{array}{l}191 \\
1930\end{array}$ \\
\hline PACIFICO & 7 & 0 & 1 & 3 \\
\hline ALAJUELA SAN RAMÓN & 3 & 2 & 1 & 1 \\
\hline ATLÁNTICA & 0 & 0 & 1 & 2 \\
\hline CENTRAL & 7 & 4 & 5 & 6 \\
\hline NORTE & 1 & 0 & 0 & 1 \\
\hline SUR & 2 & 1 & 1 & \\
\hline $\begin{array}{l}\text { R E V E N T A Z Ó N } \\
\text { PARISMINA }\end{array}$ & 1 & 0 & 3 & 2 \\
\hline
\end{tabular}


Aún ese decrecimiento en la configuración y segmentación del poder fue evidente y muy diferente al Valle Central donde tuvo que compartirse el poder local con las élites regionales y cantonales, los cuadros no 1 y 2 sugieren investigar como el crecimiento poblacional y proyecto político se fue articulando entre la denominada "Meseta Central" y la costa pacífica. Tal proyecto hizo que la lengüeta fuera tomando fuerza. De esta forma, no solo las inversiones extranjeras y la construcción de aduanas fue fortaleciendo a una elite local en contra de otras regiones cercanas al puerto, sino que también hizo que otras áreas fueran incorporadas a la lógica del puerto, como fue el caso de la denominada zona sur y Golfito.

El área del pacífico central como bien visualizaba Virgilio Caamaño en 1922 (véase mapa no. 6) desde el puerto de Puntarenas se articulo un espacio intergional que no solo se ocupó desde muy temprano de las islas, sino también de la desembocadura de los ríos Tempisque y Nacaome, articulando con ello la región de Nicoya, Santa Cruz y aún Liberia.

Mapa no. 6 Servicio de Cabotaje en el Golfo de Nicoya y Río Tempisque. Bosquejo de 1942 


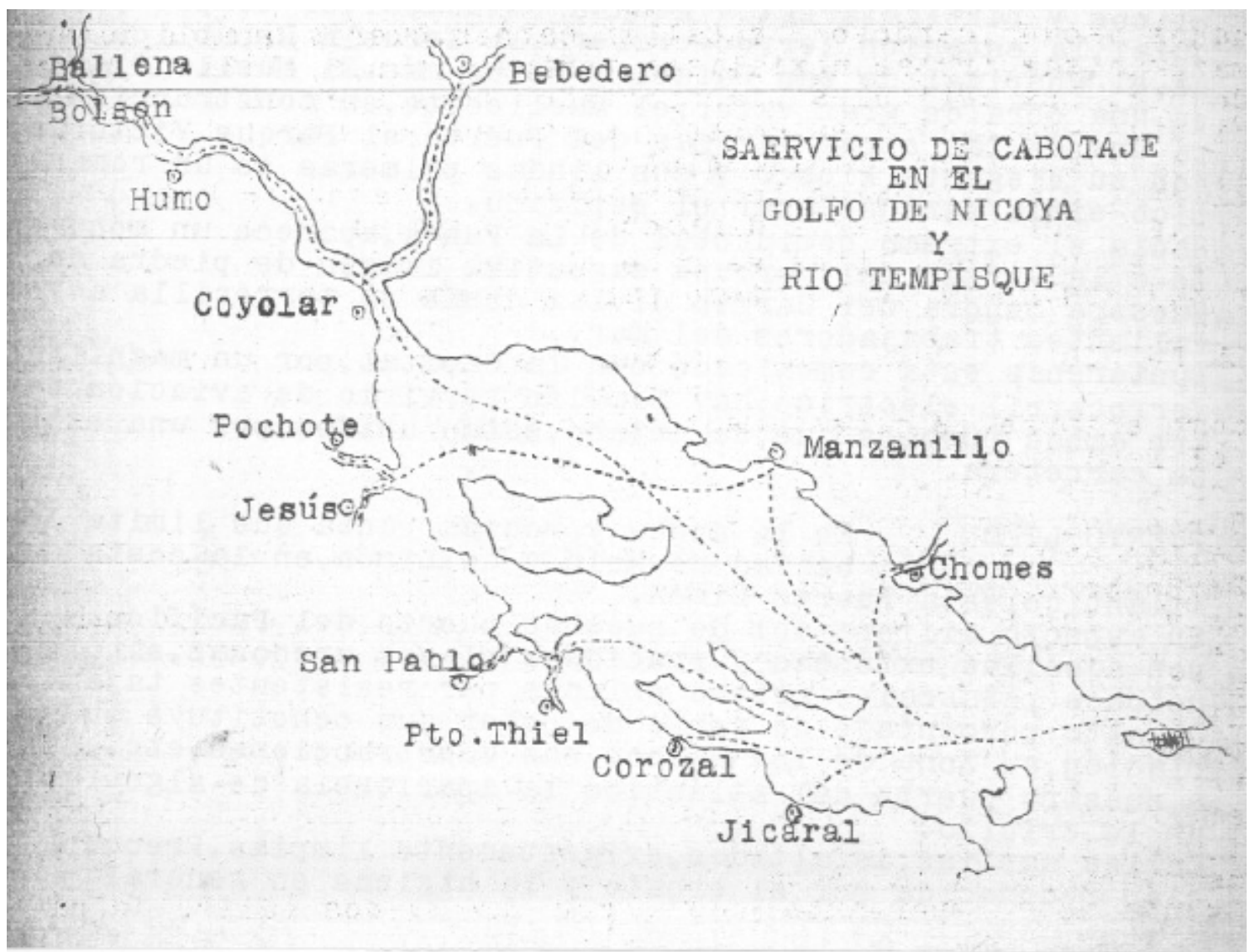

Fuente: Caamaño Virgilio El costarricense y el mar. mimeografiado. 1942

De este modo, se intensificó el comercio de sal (destacándose las salinas chireñas), maíz, carey, tubérculos; escorcionera (planta medicinal que usaron los chorotegas y corobicies para curar una serie de patologías,) y la cabuya; además de diversas frutas como marañones, limos, mangos y naranjas. Lo cual se combinaba según Caamaño con la agricultura nicoyana, los productos de cacería y la crianza de ganado.

Para Caamaño el puerto de Puntarenas era eje de tres rutas de cabotaje (las cuales coinciden con los procesos de territorilización del pacífico entre 1850 y 1950. Estas rutas eran la del Golfo de Nicoya y la senda del Tempisque. La cual como vimos permitió crear una gran articulación entre Nicoya, Santa Cruz, Bagaces, Esparza y Puntarenas, pues desde el puerto de Puntarenas se unían los llamados puertecitos de Chomes, Santa Juana, Manzanillo, Paquera, Jicaral, Carozal, Thiel, 
San Pablo, Jesús, Pochete , Humo, Bolsón, Bebedero y el Coyolar.

La segunda ruta era la denominada Vuelta de Alguera que se aventuraba fuera del Golfo para unir el pacífico norte y las costas de Guanacaste por lo cual se unía al Puerto de Puntarenas los titulados puertecitos de Coyote, Sámara, San Juanillo, Tamarindo, Puerto Viejo, Potrero y Puerto Soley. Debe indicarse que este se unía a otros procesos de cabotaje provenientes de Chiriquí, El Salvador, Nicaragua y Honduras, convirtiendo a la zona en un área interregional centroamericana.

Finalmente, estaba la ruta de cabotaje denominada del sur la cual vinculaba hasta con Panamá, desde el puerto de Puntarenas se unía Herradura, Palo Seco, Quepos, Dominical, Ballena, Dominical, Ballena, Puerto Cortés, Lagarto, Río de Térraba, Sierpe, Puerto Jiménez, Golfito, Coto, Golfo Dulce y Armuelles.

El cuadro no. 3 evidencia un fenómeno interesante de cómo un buen porcentaje de los extranjeros se nacionalizaron en las provincias costeras del pacífico de Puntarenas y Guanacaste, destacándose las ciudades de Puntarenas y Liberia.

\begin{tabular}{lll}
\multicolumn{3}{l}{ Cuadro No 3 número de naturalizados según el } \\
registro cívico de 1824 a 1927 \\
PROVINCIA & NUMERO & PORCENTAJES \\
ALA & 15 & 0,95 \\
CAR & 23 & 1,45 \\
GUA & 582 & 36,70 \\
HER & 5 & 0,32 \\
LIM & 211 & 13,30 \\
PUN & 558 & 35,18 \\
SJO & 192 & 12,11 \\
Total & 1586 & 100,00
\end{tabular}

Tal vez ese proceso de nacionalización este vinculado con este flujo de inmigrantes. Lastimosamente por espacio y tiempo no se pueden analizar los directorios comerciales para ver ese grado de vinculación. 
Finalmente, un proceso interesante de visualizar es el equipamiento urbano. El mismo es útil pues permite visibilizar las luchas entre comunidades por modernizar sus espacios; el desarrollo de la organización social y la penetración de una de las principales medidas sanitarias edificadas tanto por los liberales, como por denominados proyectos socialdemócratas y social cristiano. . Según la colección de leyes y decretos indexada en el Sistema Costarricense de Información Jurídica (http://www.pgr.go.cr/Scij/) este proceso de equipamiento urbano comenzó a principios de siglo (con otros procesos como el de electricidad, sanidad y vacunación, entre otros). No obstante fue en las décadas de 1920 y 1940 que el proceso logró grandes dimensiones.

Cuadro 4. Número de decretos con respecto a las cañerías, 1850-2008

1850-1869

1

1870-1899

10

1900-1919

65

1920-1949

149

1950-1969

14

1970-1999

5

2000-2008

1

245

Fuente: leyes de decretos de la República de Costa Rica, 1824-2008

Sistema Costarricense de Información Jurídica (http://www. pgr.go.cr/Scij/.

El fenómeno del equipamiento fue diferenciado en lo regional, como se puede notar en el cuadro no. 5 las provincias de San José y Alajuela tuvieron la mayor concentración de los servicios, como se demuestra el anexo 2., hay que considerar que en estas provincias la extensión del servicio pudo deberse al empuje de un gran número de elites locales y a la mayor organización social. 
El cuadro 5. Distribución de los decretos relacionados a las cañerías por provincias, $1850-2008$

Frecuencia Porcentaje Porcentaje Válido Porcentaje Acumulado

$\begin{array}{lllll}\text { ALA } & 48 & 19,6 & 19,6 & 19,6 \\ \text { CAR } & 34 & 13,9 & 13,9 & 33,5 \\ \text { CR } & 12 & 4,9 & 4,9 & 38,4 \\ \text { GUA } & 19 & 7,8 & 7,8 & 46,1 \\ \text { HER } & 25 & 10,2 & 10,2 & 56,3 \\ \text { LIM } & 4 & 1,6 & 1,6 & 58,0 \\ \text { PUN } & 20 & 8,2 & 8,2 & 66,1 \\ \text { SJO } & 83 & 33,9 & 33,9 & 100,0 \\ \text { Total } & 245 & 100 & 100 & \end{array}$

Fuente: leyes de decretos de la República de Costa Rica, 1824-2008 Sistema

Costarricense de Información Jurídica (http://www.pgr.go.cr/Scij/

Ahora bien, cómo se desarrolló este fenómeno en la costa pacífica. El gráfico no 2 nos muestra la expansión que hubo. Los primeros beneficiados fueron Liberia y Puntarenas pero con una distancia que osciló entre tres y cuatro décadas con respecto a la capital. Si bien el atraso es monumental, algunos servicios de equipamiento posteriores fueron reducidos en tiempo, esto gracias a la acción de las comunidades y a la concepción del estado desarrollista.

Gráfico 2. Gráfico Radial sobre las distancias de llegada de la cañería en la costa pacífica, tomando como base la ciudad de San José según la colección de leyes y decretos 1824 $-2008$ 


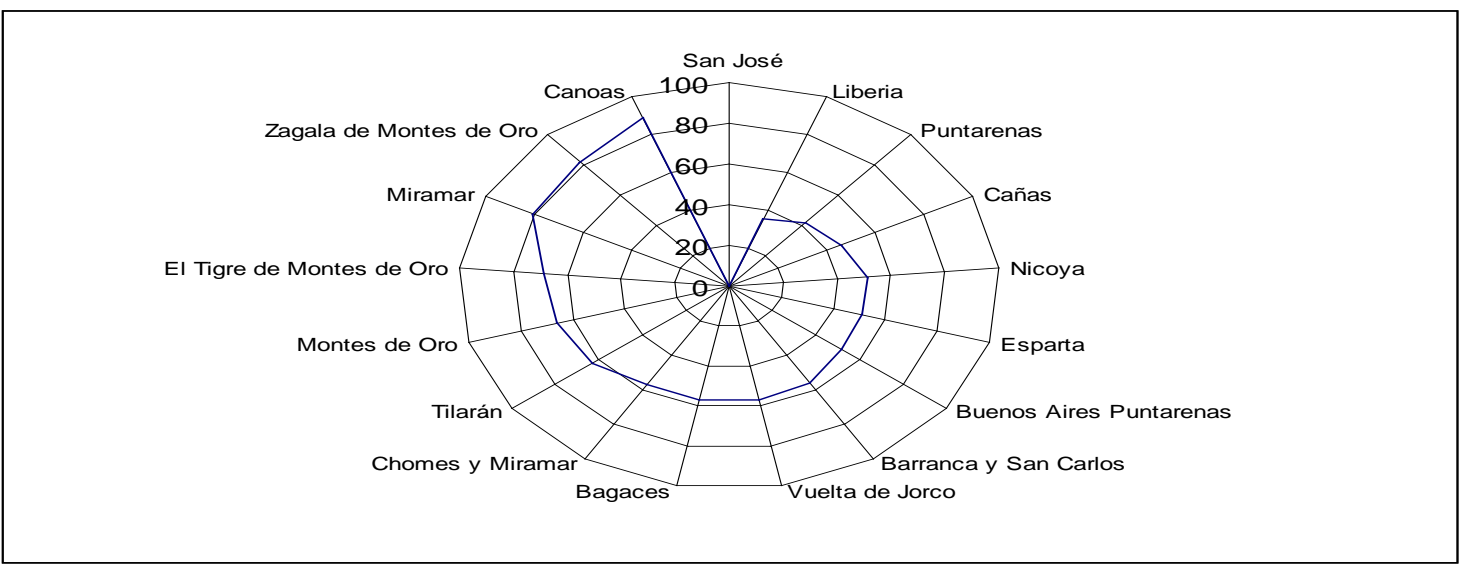

Fuente: leyes de decretos de la República de Costa Rica, 1824-2008 Sistema Costarricense de Información Jurídica (http://www.pgr.go.cr/Scij/

Nicoya, Esparta y Buenos Arias tuvieron a su vez una distancia temporal alta entre Liberia y Puntarenas que oscilaron entre tres y cuatro lustros y con respecto a san José casi medio siglo. El caso más extremoso fue el de Canoas que casi tuvo un siglo de atraso. Si bien es cierto, el proceso de cañería fue mejorado varias veces y existió una red de acueductos locales, basados en acequías estos no explican el atraso de la colaboración estatal. De este modo, el indicador señalado nos llama la atención de los puntos de diferenciación social, y que se podrían ejemplificar aún más con educación y salud.

\section{EPILOGO}

En suma, el argumento esencial de esta ponencia es que el concepto de región debe verse como una hipótesis de trabajo del historiador al mismo tiempo que debe ser concebida como una construcción social cambiante en el tiempo, diversa, múltiple y llena de procesos internos y contradictorios. Pero a pesar de lo caótico que pueda resultar esta perspectiva lo fundamental es verla como una problemática que hay que trabajar construyendo herramientas teórico 
metodológicas.

En ese sentido, las regiones son buenas excusas para pensar, es decir, para plantear problemas en forma sugerente y para acercarnos de una manera nueva y fecunda a los problemas que desde hace mucho tiempo preocupan a los estudiosos de la historia social. Tan sólo plantearse la región como una hipótesis de trabajo ya la convertiría en una poderosa herramienta de interpretativa. Refiriéndose a los estudios rurales, Eric Van Young ha dicho que la perspectiva regional ha mostrado su superioridad, pues ha logrado combinar "la profundidad del enfoque micro histórico con la amplitud del análisis estructural”.

Esta ponencia solo ha tenido el interés de ubicar posibles vías de análisis que cuestionen a la historia oficial e ideológica con una historia social regional de tipo comparada que nos lleva a comprender los procesos de configuración social con sus procesos de desigualdad, cohesión y esperanza social reflejados en identidades, utopías y proyectos políticos alternativos. 
9 90 CONGRESO

Indexaciones: Repositorio de Revistas UCR, DIALNET, Latindex, REDALYC Directorio y recolector de recursos digitales del Ministerio de Cultura de España, Directory of Open Access Journals. Diálogos Revista Electrónica de Historia ISSN 1409- 469X. Número especial 2008. Dirección web: http://historia.fcs.ucr.ac.cr/dialogos.htm

\section{ANEXO 1}

Ubicación por provincia de las nacionalidades según el Registro de Naturalizaciones 1824-1927

\begin{tabular}{|c|c|c|c|c|c|c|c|c|c|}
\hline & \multicolumn{8}{|c|}{ PROV } & Total \\
\hline NACIONALIDAD & & ALA & CAR & GUA & HER & LIM & PUN & SJO & \\
\hline EL SALVADOR & 1 & 0 & 0 & 0 & 0 & 0 & 0 & 0 & 1 \\
\hline ALEMANIA & 70 & 0 & 0 & 1 & 0 & 1 & 3 & 15 & 90 \\
\hline ARABIA & 1 & 0 & 0 & 0 & 0 & 0 & 0 & 0 & 1 \\
\hline AUSTRIA & 9 & 0 & 0 & 0 & 0 & 0 & 0 & 0 & 9 \\
\hline BAHAMAS & 1 & 0 & 0 & 0 & 0 & 0 & 0 & 0 & 1 \\
\hline BARBADOS & 3 & 0 & 0 & 0 & 0 & 0 & 0 & 0 & 3 \\
\hline BELGICA & 1 & 0 & 0 & 0 & 0 & 0 & 0 & 0 & 1 \\
\hline BELICE, HONDURAS BRITANICA & 1 & 0 & 0 & 0 & 0 & 0 & 0 & 0 & 1 \\
\hline CHECOSLOVAQUIA & 3 & 0 & 0 & 0 & 0 & 0 & 0 & 0 & 3 \\
\hline CHILE & 4 & 0 & 0 & 0 & 0 & 0 & 0 & 1 & 5 \\
\hline CHINA & 119 & 0 & 1 & 1 & 0 & 0 & 6 & 2 & 129 \\
\hline COLOMBIA & 171 & 0 & 1 & 0 & 0 & 1 & 29 & 7 & 209 \\
\hline CROACIA & 2 & 0 & 0 & 0 & 0 & 0 & 0 & 0 & 2 \\
\hline CUBA & 63 & 2 & 4 & 0 & 0 & 0 & 4 & 3 & 76 \\
\hline DINAMARCA & 14 & 0 & 0 & 0 & 0 & 0 & 0 & 2 & 16 \\
\hline E. U.A & 22 & 0 & 0 & 0 & 0 & 1 & 1 & 2 & 26 \\
\hline ECUADOR & 8 & 0 & 0 & 0 & 0 & 0 & 0 & 0 & 8 \\
\hline EL SALVADOR & 38 & 1 & 0 & 4 & 3 & 1 & 1 & 2 & 50 \\
\hline ESPAÑA & 167 & 0 & 1 & 0 & 0 & 1 & 3 & 35 & 207 \\
\hline FINLANDIA & 1 & 0 & 0 & 0 & 0 & 0 & 0 & 0 & 1 \\
\hline FRANCIA & 49 & 0 & 0 & 1 & 0 & 0 & 0 & 20 & 70 \\
\hline GRAN LIBANO & 1 & 0 & 0 & 0 & 0 & 0 & 0 & 0 & 1 \\
\hline GRECIA & 2 & 0 & 0 & 0 & 0 & 0 & 0 & 0 & 2 \\
\hline GUATEMALA & 14 & 4 & 0 & 1 & 0 & 3 & 3 & 17 & 42 \\
\hline HAITI & 2 & 0 & 0 & 0 & 0 & 0 & 0 & 0 & 2 \\
\hline HEBREO & 1 & 0 & 0 & 0 & 0 & 0 & 0 & 0 & 1 \\
\hline HOLANDA & 2 & 0 & 0 & 0 & 0 & 0 & 0 & 1 & 3 \\
\hline HONDURAS & 29 & 1 & 2 & 13 & 0 & 9 & 29 & 8 & 91 \\
\hline HUNGRIA & 1 & 0 & 0 & 0 & 0 & 0 & 0 & 0 & 1 \\
\hline INDIA & 2 & 0 & 0 & 0 & 0 & 0 & 0 & 0 & 2 \\
\hline INGLATERRA & 55 & 0 & 0 & 1 & 0 & 1 & 2 & 5 & 64 \\
\hline ITALIA & 67 & 0 & 11 & 0 & 0 & 2 & 3 & 13 & 96 \\
\hline
\end{tabular}


19. CONGRESO

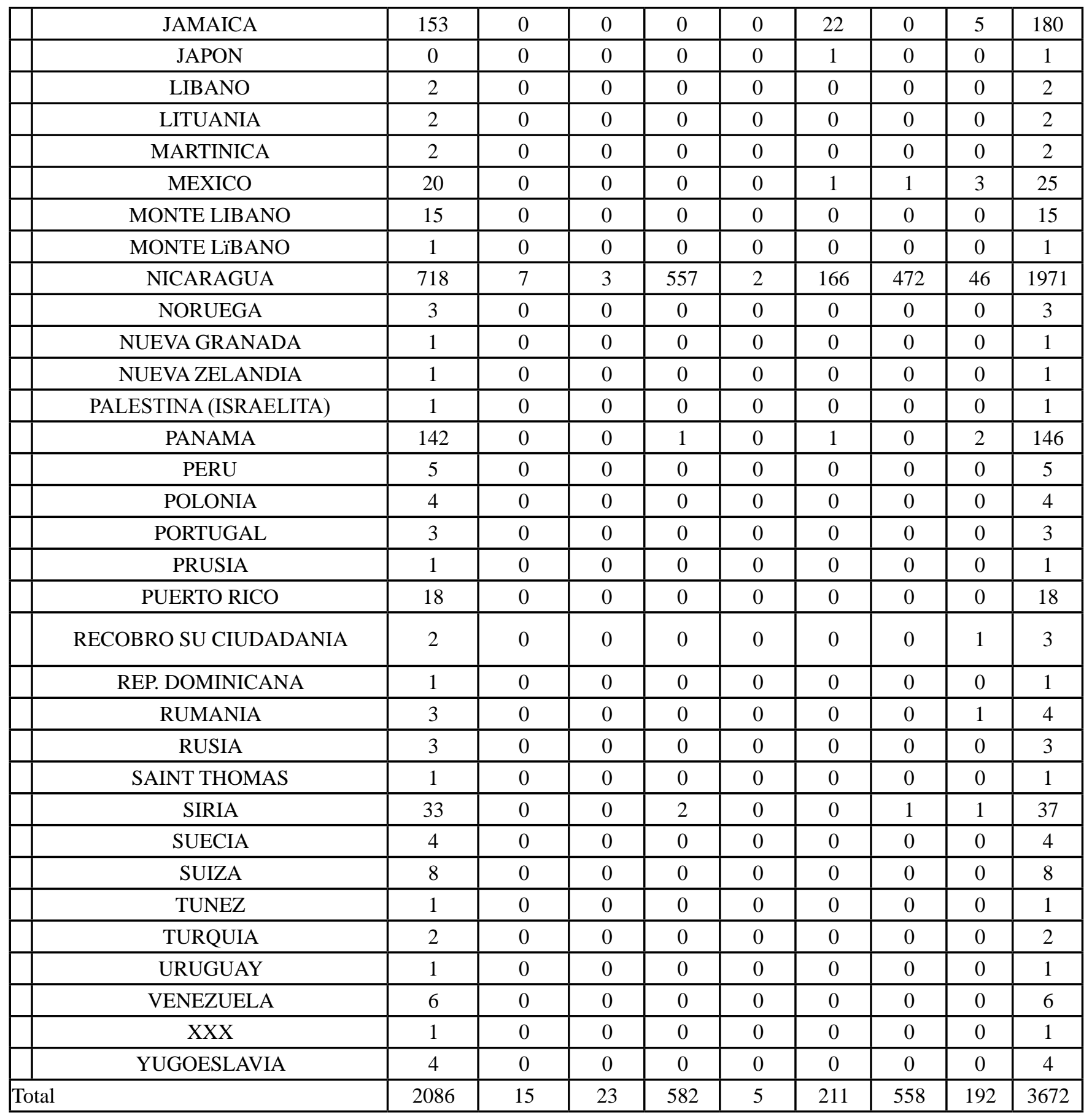


Distribución de las disposiciones sobre las cañerías según lugar y Provincia

\begin{tabular}{|c|c|c|c|c|c|c|c|c|c|}
\hline \multirow[b]{2}{*}{ lugar } & \multicolumn{8}{|c|}{ Provincia } & \multirow{3}{*}{$\begin{array}{c}\text { Total } \\
1\end{array}$} \\
\hline & ALA & CAR & CR & GUA & HER & LIM & PUN & SJO & \\
\hline Cartago & 0 & 1 & 0 & 0 & 0 & 0 & 0 & 0 & \\
\hline El Yas de Paraíso de Cartago & 0 & 1 & 0 & 0 & 0 & 0 & 0 & 0 & 1 \\
\hline Heredia & 0 & 0 & 0 & 0 & 1 & 0 & 0 & 0 & 1 \\
\hline Puriscal & 0 & 0 & 0 & 0 & 0 & 0 & 0 & 1 & 1 \\
\hline San José & 0 & 0 & 0 & 0 & 0 & 0 & 0 & 1 & 1 \\
\hline Abangares & 0 & 0 & 0 & 1 & 0 & 0 & 0 & 0 & 1 \\
\hline Alajuela & 3 & 0 & 0 & 0 & 0 & 0 & 0 & 0 & 3 \\
\hline Alajuelita & 0 & 0 & 0 & 0 & 0 & 0 & 0 & 2 & 2 \\
\hline Aranjuez San José & 0 & 0 & 0 & 0 & 0 & 0 & 0 & 1 & 1 \\
\hline Atenas & 7 & 0 & 0 & 0 & 0 & 0 & 0 & 0 & 7 \\
\hline Bagaces & 0 & 0 & 0 & 4 & 0 & 0 & 0 & 0 & 4 \\
\hline Barba & 0 & 0 & 0 & 0 & 1 & 0 & 0 & 0 & 1 \\
\hline Barranca y San Carlos & 0 & 0 & 0 & 0 & 0 & 0 & 1 & 0 & 1 \\
\hline Barrio Canoas de Alajuela & 1 & 0 & 0 & 0 & 0 & 0 & 0 & 0 & 1 \\
\hline Barrio El Rosario de Naranjo & 1 & 0 & 0 & 0 & 0 & 0 & 0 & 0 & 1 \\
\hline Brasil de Mora & 0 & 0 & 0 & 0 & 0 & 0 & 0 & 1 & 1 \\
\hline Buenos Aires Puntarenas & 0 & 0 & 0 & 0 & 0 & 0 & 1 & 0 & 1 \\
\hline Canoas & 0 & 0 & 0 & 0 & 0 & 0 & 1 & 0 & 1 \\
\hline Cañas & 0 & 0 & 0 & 1 & 0 & 0 & 0 & 0 & 1 \\
\hline Carmen Cartago & 0 & 1 & 0 & 0 & 0 & 0 & 0 & 0 & 1 \\
\hline Carmen de Cartago & 0 & 1 & 0 & 0 & 0 & 0 & 0 & 0 & 1 \\
\hline Carrillo de Poás & 1 & 0 & 0 & 0 & 0 & 0 & 0 & 0 & 1 \\
\hline Cartago & 0 & 4 & 0 & 0 & 0 & 0 & 0 & 0 & 4 \\
\hline Cetillal & 0 & 0 & 0 & 0 & 0 & 0 & 0 & 1 & 1 \\
\hline Chomes y Miramar & 0 & 0 & 0 & 0 & 0 & 0 & 1 & 0 & 1 \\
\hline Ciudad Quesada & 1 & 0 & 0 & 0 & 0 & 0 & 0 & 0 & 1 \\
\hline Concepción de La Unión & 0 & 1 & 0 & 0 & 0 & 0 & 0 & 0 & 1 \\
\hline Coronado & 0 & 0 & 0 & 0 & 0 & 0 & 0 & 2 & 2 \\
\hline Cot & 0 & 1 & 0 & 0 & 0 & 0 & 0 & 0 & 1 \\
\hline
\end{tabular}


$99^{\circ}$ CONGRESO

CENTROAMERICANO

UL IIISIORIA

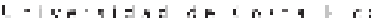

Indexaciones: Repositorio de Revistas UCR, DIALNET, Latindex, REDALYC Directorio y recolector de recursos digitales del Ministerio de Cultura de España, Directory of Open Access Journals. Diálogos Revista Electrónica de Historia ISSN 1409- 469X. Número especial 2008. Dirección web: http://historia.fcs.ucr.ac.cr/dialogos.htm

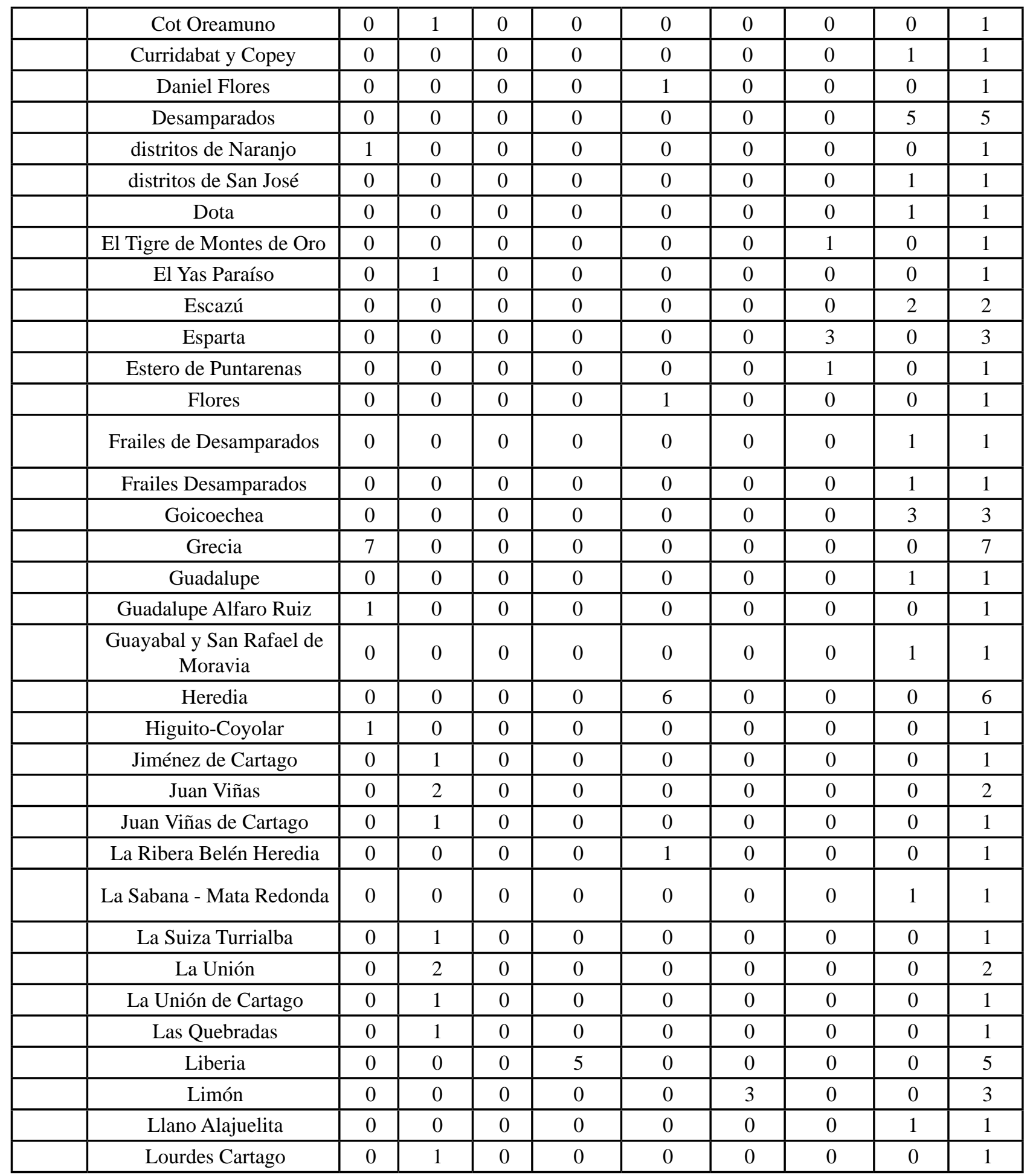




\begin{tabular}{|c|c|c|c|c|c|c|c|c|c|}
\hline Miramar & 0 & 0 & 0 & 0 & 0 & 0 & 2 & 0 & 2 \\
\hline Montes de Oca & 0 & 0 & 0 & 0 & 0 & 0 & 0 & 2 & 2 \\
\hline Montes de Oro & 0 & 0 & 0 & 0 & 0 & 0 & 1 & 0 & 1 \\
\hline Montes Oro & 0 & 0 & 0 & 0 & 0 & 0 & 1 & 0 & 1 \\
\hline Mora & 0 & 0 & 0 & 0 & 0 & 0 & 0 & 1 & 1 \\
\hline Moravia & 0 & 0 & 0 & 0 & 0 & 0 & 0 & 2 & 2 \\
\hline Nacional & 0 & 0 & 12 & 0 & 0 & 0 & 0 & 0 & 12 \\
\hline Naranjo & 2 & 0 & 0 & 0 & 0 & 0 & 0 & 0 & 2 \\
\hline Naranjo Grecia Santa Ana & 1 & 0 & 0 & 0 & 0 & 0 & 0 & 0 & 1 \\
\hline Nicoya & 0 & 0 & 0 & 2 & 0 & 0 & 0 & 0 & 2 \\
\hline Oreamuno & 0 & 1 & 0 & 0 & 0 & 0 & 0 & 0 & 1 \\
\hline Pacayas & 0 & 1 & 0 & 0 & 0 & 0 & 0 & 0 & 1 \\
\hline Pacayas y Cervantes, Cartago & 0 & 1 & 0 & 0 & 0 & 0 & 0 & 0 & 1 \\
\hline Palmares & 2 & 0 & 0 & 0 & 0 & 0 & 0 & 0 & 2 \\
\hline Paracito & 0 & 0 & 0 & 0 & 2 & 0 & 0 & 0 & 2 \\
\hline Paraíso & 0 & 2 & 0 & 0 & 0 & 0 & 0 & 0 & 2 \\
\hline Paraíso de Cartago & 0 & 1 & 0 & 0 & 0 & 0 & 0 & 0 & 1 \\
\hline Patarrá & 0 & 0 & 0 & 0 & 0 & 0 & 0 & 1 & 1 \\
\hline Pavas de San José & 0 & 0 & 0 & 0 & 0 & 0 & 0 & 1 & 1 \\
\hline Pérez Zeledón & 0 & 0 & 0 & 0 & 0 & 0 & 0 & 1 & 1 \\
\hline Piedades de Santa Ana & 0 & 0 & 0 & 0 & 0 & 0 & 0 & 2 & 2 \\
\hline Pizote-Estanque de Tres Ríos & 0 & 1 & 0 & 0 & 0 & 0 & 0 & 0 & 1 \\
\hline Praga Aserrí & 0 & 0 & 0 & 0 & 0 & 0 & 0 & 1 & 1 \\
\hline Puntarenas & 0 & 0 & 0 & 0 & 0 & 0 & 6 & 0 & 6 \\
\hline Puriscal, Turrubares y Mora & 0 & 0 & 0 & 0 & 0 & 0 & 0 & 1 & 1 \\
\hline $\begin{array}{c}\text { Quebradas Santo Domingo } \\
\text { Heredia } \\
\end{array}$ & 0 & 0 & 0 & 0 & 1 & 0 & 0 & 0 & 1 \\
\hline Ramón & 1 & 0 & 0 & 0 & 0 & 0 & 0 & 0 & 1 \\
\hline Sabanilla & 0 & 0 & 0 & 0 & 0 & 0 & 0 & 1 & 1 \\
\hline San Gabriel de Aserrí & 0 & 0 & 0 & 0 & 0 & 0 & 0 & 1 & 1 \\
\hline San Grabriel de Aserrí & 0 & 0 & 0 & 0 & 0 & 0 & 0 & 1 & 1 \\
\hline San Jerónimo de Grecia & 1 & 0 & 0 & 0 & 0 & 0 & 0 & 0 & 1 \\
\hline San José & 0 & 0 & 0 & 0 & 0 & 0 & 0 & 6 & 6 \\
\hline San José barrios del sur & 0 & 0 & 0 & 0 & 0 & $\overline{0}$ & 0 & 1 & 1 \\
\hline San José Barrios Sur & 0 & 0 & 0 & 0 & 0 & 0 & 0 & 1 & 1 \\
\hline
\end{tabular}




\begin{tabular}{|c|c|c|c|c|c|c|c|c|c|}
\hline San Juan de Dios & 0 & 0 & 0 & 0 & 0 & 0 & 0 & 1 & 1 \\
\hline $\begin{array}{c}\text { San Juan de Dios de } \\
\text { Desamparados } \\
\end{array}$ & 0 & 0 & 0 & 0 & 0 & 0 & 0 & 2 & 2 \\
\hline San Juan de Poás & 1 & 0 & 0 & 0 & 0 & 0 & 0 & 0 & 1 \\
\hline $\begin{array}{c}\text { San Juan y San Vicente San } \\
\text { José }\end{array}$ & 0 & 0 & 0 & 0 & 0 & 0 & 0 & 1 & 1 \\
\hline San Juanillo del Naranjo & 1 & 0 & 0 & 0 & 0 & 0 & 0 & 0 & 1 \\
\hline San Luis Sabanilla & 0 & 0 & 0 & 0 & 0 & 0 & 0 & 1 & 1 \\
\hline San Mateo & 2 & 0 & 0 & 0 & 0 & 0 & 0 & 0 & 2 \\
\hline San Mateo a Alto Surubres & 1 & 0 & 0 & 0 & 0 & 0 & 0 & 0 & 1 \\
\hline San Miguel Sarapiquí & 0 & 0 & 0 & 0 & 1 & 0 & 0 & 0 & 1 \\
\hline San Pablo de Tarrazú & 0 & 0 & 0 & 0 & 0 & 0 & 0 & 1 & 1 \\
\hline $\begin{array}{c}\text { San Pablo Mercedes Barreal } \\
\text { San Francisco Heredia }\end{array}$ & 0 & 0 & 0 & 0 & 1 & 0 & 0 & 0 & 1 \\
\hline San Pedro de Montes de Oca & 0 & 0 & 0 & 0 & 0 & 0 & 0 & 1 & 1 \\
\hline San Pedro de Turrubares & 1 & 0 & 0 & 0 & 0 & 0 & 0 & 0 & 1 \\
\hline San Pedro de Turrúcares & 1 & 0 & 0 & 0 & 0 & 0 & 0 & 0 & 1 \\
\hline $\begin{array}{c}\text { San Pedro del Mojón San } \\
\text { José }\end{array}$ & 0 & 0 & 0 & 0 & 0 & 0 & 0 & 1 & 1 \\
\hline San Rafael de Escazú & 0 & 0 & 0 & 0 & 0 & 0 & 0 & 1 & 1 \\
\hline San Rafael de Heredia & 0 & 0 & 0 & 0 & 1 & 0 & 0 & 0 & 1 \\
\hline San Ramón & 4 & 0 & 0 & 0 & 0 & 0 & 0 & 0 & 4 \\
\hline San Roque Grecia & 1 & 0 & 0 & 0 & 0 & 0 & 0 & 0 & 1 \\
\hline San Vicente Cantón Moravia & 0 & 0 & 0 & 0 & 0 & 0 & 0 & 1 & 1 \\
\hline Santa Ana & 0 & 0 & 0 & 0 & 0 & 0 & 0 & 2 & 2 \\
\hline Santa Bárbara & 0 & 0 & 0 & 0 & 1 & 0 & 0 & 0 & 1 \\
\hline Santa María de Dota & 0 & 0 & 0 & 0 & 0 & 0 & 0 & 1 & 1 \\
\hline Santiago de Paraíso Cartago & 0 & 1 & 0 & 0 & 0 & 0 & 0 & 0 & 1 \\
\hline Santiago de Puriscal & 0 & 0 & 0 & 0 & 0 & 0 & 0 & 4 & 4 \\
\hline Santiago Puriscal & 0 & 0 & 0 & 0 & 0 & 0 & 0 & 1 & 1 \\
\hline Santo Domingo & 0 & 0 & 0 & 0 & 3 & 0 & 0 & 0 & 3 \\
\hline Santo Domingo de Heredia & 0 & 0 & 0 & 0 & 2 & 0 & 0 & 0 & 2 \\
\hline Santo Domingo Heredia & 0 & 0 & 0 & 0 & 1 & 0 & 0 & 0 & 1 \\
\hline
\end{tabular}


Indexaciones: Repositorio de Revistas UCR, DIALNET, Latindex, REDALYC Directorio y recolector de recursos digitales del Ministerio de Cultura de España, Directory of Open Access Journals. Diálogos Revista Electrónica de Historia ISSN 1409- 469X. Número especial 2008. Dirección web: http://historia.fcs.ucr.ac.cr/dialogos.htm

\begin{tabular}{|c|c|c|c|c|c|c|c|c|c|c|}
\hline & $\begin{array}{c}\text { Sector Norte de Pedregoso de } \\
\text { Pérez Zeledón, San José }\end{array}$ & 0 & 0 & 0 & 0 & 0 & 0 & 0 & 1 & 1 \\
\hline & Siquirres & 0 & 0 & 0 & 0 & 0 & 1 & 0 & 0 & 1 \\
\hline & $\begin{array}{l}\text { Sto Domingo de Santa } \\
\text { Bárbara de Heredia }\end{array}$ & 0 & 0 & 0 & 0 & 1 & 0 & 0 & 0 & 1 \\
\hline & Tarrazú & 0 & 0 & 0 & 0 & 0 & 0 & 0 & 3 & 3 \\
\hline & Tibas & 0 & 0 & 0 & 0 & 0 & 0 & 0 & 1 & 1 \\
\hline & Tibás & 0 & 0 & 0 & 0 & 0 & 0 & 0 & 3 & 3 \\
\hline & Tibás y Moravia & 0 & 0 & 0 & 0 & 0 & 0 & 0 & 1 & 1 \\
\hline & Tierra Blanca & 0 & 1 & 0 & 0 & 0 & 0 & 0 & 0 & 1 \\
\hline & Tilarán & 0 & 0 & 0 & 5 & 0 & 0 & 0 & 0 & 5 \\
\hline & Turrialba & 0 & 3 & 0 & 0 & 0 & 0 & 0 & 0 & 3 \\
\hline & Turrubares & 1 & 0 & 0 & 0 & 0 & 0 & 0 & 0 & 1 \\
\hline & Turrúcares & 0 & 0 & 0 & 0 & 0 & 0 & 0 & 1 & 1 \\
\hline & Urasca de Paraíso & 0 & 0 & 0 & 0 & 0 & 0 & 0 & 1 & 1 \\
\hline & Villa Acosta & 0 & 0 & 0 & 0 & 0 & 0 & 0 & 1 & 1 \\
\hline & Villa Quesada & 1 & 0 & 0 & 0 & 0 & 0 & 0 & 0 & 1 \\
\hline & Vuelta de Jorco & 0 & 0 & 0 & 1 & 0 & 0 & 0 & 1 & 2 \\
\hline & Zagala de Montes de Oro & 0 & 0 & 0 & 0 & 0 & 0 & 1 & 0 & 1 \\
\hline & $\begin{array}{l}\text { Zapote, San Francisco Dos } \\
\text { Ríos }\end{array}$ & 0 & 0 & 0 & 0 & 0 & 0 & 0 & 1 & 1 \\
\hline & Zarcero & 3 & 0 & 0 & 0 & 0 & 0 & 0 & 0 & 3 \\
\hline Total & & 48 & 34 & 12 & 19 & 25 & 4 & 20 & 83 & 245 \\
\hline
\end{tabular}

